OPEN ACCESS

Edited by:

Vincenzo Tufarelli,

University of Bari Aldo Moro, Italy

Reviewed by:

Geoffrey E. Dahl,

University of Florida, United States

Umberto Bernabucci,

Università degli Studi della

Tuscia, Italy

${ }^{*}$ Correspondence:

Mariangela Caroprese mariangela.caroprese@unifg.it

Specialty section:

This article was submitted to Animal Nutrition and Metabolism,

a section of the journal

Frontiers in Veterinary Science

Received: 13 November 2019

Accepted: 08 January 2020

Published: 20 February 2020

Citation:

Ciliberti MG, Albenzio M, De Palo P, Santillo A and Caroprese M (2020) Nexus Between Immune Responses and Oxidative Stress: The Role of Dietary Hydrolyzed Lignin in ex vivo Bovine Peripheral Blood Mononuclear

Cell Response. Front. Vet. Sci. 7:9. doi: 10.3389/fvets.2020.00009

\section{Nexus Between Immune Responses and Oxidative Stress: The Role of Dietary Hydrolyzed Lignin in ex vivo Bovine Peripheral Blood Mononuclear Cell Response}

\author{
Maria Giovanna Ciliberti ${ }^{1}$, Marzia Albenzio ${ }^{1}$, Pasquale De Palo ${ }^{2}$, Antonella Santillo ${ }^{1}$ and \\ Mariangela Caroprese ${ }^{1 *}$
}

${ }^{1}$ Department of Sciences of Agriculture, Food and Environment, University of Foggia, Foggia, Italy, ${ }^{2}$ Department of Veterinary Medicine, University of Bari A. Moro, Bari, Italy

The control of immune responses is particularly critical when an increase of oxidative stress occurs, causing an impairment of immune cell response and a condition of systemic inflammation, named oxinflammation. Nutritional strategies based on the use in the diet of phytochemicals extracted from plants, rich in antioxidants, could help restore the antioxidant/oxidant balance and obtain a modulation of immune response. Lignin represents a valuable resource of phenolic compounds, which are characterized by a corroborated antioxidant effect. To date, there are no studies reporting the effects of lignin in the diet on immune responses and oxidative stress in ruminants. The objective of the present experiment was the evaluation of the dietary inclusion of Pinus taeda hydrolyzed lignin on the ex vivo immune responses and oxidative stress biomarkers by peripheral blood mononuclear cells (PBMCs) isolated from beef steers. In order to test the effect during oxidative stress exposition, cells were treated with hydrogen peroxide $\left(\mathrm{H}_{2} \mathrm{O}_{2}\right)$. The proliferation test and the viability assay were carried out on cells, whereas, on supernatants, the cytokine profile and the oxidative stress biomarkers were evaluated. The dietary inclusion with $P$. taeda hydrolyzed lignin resulted in cytoprotection after $\mathrm{H}_{2} \mathrm{O}_{2}$ exposition, increasing the number of viable monocytes and decreasing the reactive oxygen/nitrogen species production in supernatants. The cytokine profile indicated the modulatory role of hydrolyzed lignin on immune response, with a concomitant decrease of TNF- $\alpha$ and increase of IL-8 production, which are strictly connected with monocyte activation and antioxidant response pathway. These results demonstrated that hydrolyzed lignin may provide a modulation of oxidative stress and inflammatory response in PBMCs; thus, the P. taeda hydrolyzed lignin could be suggested as an innovative phytochemical in ruminant feed.

Keywords: ruminants, polyphenols, immune system, oxidative stress, cytokines, antioxidant response 


\section{INTRODUCTION}

An inflammatory process can be originated by different stimuli that activate a physiological response with the aim of restoring homeostasis and controlling the internal constant milieu. The interconnected pathways of immune response, the innate and adaptive response, contributed to each other to protect the organism against pathogens or stressors capable of initiating an immune response. Moreover, when passing from innate to adaptive response, the interactions among phagocytic cells, $\mathrm{T}$ cells, dendritic cells (DCs), and regulatory $\mathrm{T}$ (Treg) cells are principally controlled by both intra- and extracellular redox environments (1). Under physiological conditions, the proper function of $\mathrm{T}$ cells is guaranteed by the equilibrium between reactive oxygen species (ROS) and antioxidant systems; thus, $\mathrm{T}$ cells displayed a controlled immune response. However, the alteration or accumulation of extracellular ROS and reactive nitrogen species (RNS) can alter the immune responses that can generate a systemic inflammatory status mainly induced by oxidative stress (OS) (2). Recently, the term "oxinflammation" has been introduced in order to explain the nexus that links chronic and systemic OS to mild chronic inflammation that negatively affects immune reactivity supporting adaptive responses and increasing the susceptibility to disease (3).

Nutritional strategies in animal feed including the supplementation of polyphenol-rich by-products could represent a model of circular economy to which the global market of foodfeed production is oriented. Numerous phytochemicals have attracted scientific attention for their anti-inflammatory activity and modulating biological responses of the animals, as well as modulating rumen microbiome and improving meat/milk quality $(4,5)$. Interestingly, nutrigenomics study, both in human and in laboratory animals, demonstrated that nutraceutical compounds can affect gene expression, signaling processes, and other important processes, including cell apoptosis, immune modulation, and metabolism (6-9). A study on ovine neutrophils activated with phorbol myristate acetate (PMA) and treated with phytochemical extracts showed a modulation of their functions with an enhancement of anti-inflammatory effects by a reduction of cell adhesion and superoxide dismutase (SOD) production (10). Secretome can be defined by the secretory proteins from cells or organs, essential for signal transduction with specific membrane receptors and factors aiming at proliferation, growth, migration, and metabolism regulation (11). Cytokines are considered a key factor of the secretome; in particular, pro-inflammatory cytokines, such as tumor necrosis factor (TNF)- $\alpha$, are able to activate the nuclear factor kappa-light-chain-enhancer pathway of activated B cells $(\mathrm{NF \kappa B})$ with enhancement of NADPH oxidase (NOX) activity in the mitochondria and increase of production of free radicals (12). Dietary phytochemicals from Vaccinium myrtiullus and Curcuma longa down-regulated mRNA expression of TNF- $\alpha$ and (NFKB) in sheep peripheral blood cells with a reduction of ceruloplasmin (13). Moreover, several aromatic plants and their secondary metabolites have been found to exert immunomodulatory actions when animals are immune-suppressed, improving phagocytosis, modulating immunoglobulin and cytokine secretion, enhancing lymphocyte expression, and boosting the release of interferon (IFN)- $\gamma$ (14).

Supplementation with Pinus taeda hydrolized lignin (PTHL) of beef steers was found to be a proper additive for controlling methane production without any negative effects in terms of digestibility and production performance (5). Lignin represents a resource of phenolic compounds being transformed via hydroxyalkylation; furthermore, the application of phenolic resins from lignin is predicted to grow to 16 billion USD by 2025 (15) with a stable market value with a price of 1.22 $1.46 \mathrm{USD} / \mathrm{kg}$. Currently, phenols are produced from petroleumbased benzene by cumene process and are used in chemical, pharmaceutical, food, and perfumery industry (16). Phenolic compounds have largely demonstrated to have antioxidants and anti-inflammatory effects, in both in vivo and in vitro studies. No previous studies investigated the immunological effect of PTHL in ruminants. Our hypothesis was that dietary inclusion of lignin as phytochemical could improve the immune and antioxidant status of animals. Therefore, the present study aimed at understanding the role of PTHL on peripheral blood mononuclear cell (PBMC) proliferation, apoptosis, cytokine secretion, and antioxidant/oxidant balance.

\section{MATERIALS AND METHODS}

\section{Animals}

The animal experiment was performed with approval from Ethics Committee for animal testing-CESA (process number 2-X/17). The experimental design was previously reported by Maggiolino et al. (5). Briefly, 40 Limousine steers (6 months old) were randomly subdivided into two groups; the experimental group received the supplementation with $P$. taeda hydrolized lignin (PTHL, initial mean live weight $339 \mathrm{~kg}$, Oxyphenol ${ }^{\circledR}$, I-Green, Padua, Italy), whereas the control (CON, initial mean live weight $340 \mathrm{~kg}$ ) group did not receive supplementation. The experimental groups were fed ad libitum with the same total mixed ratio (TMR), for 120 days, until 10 months of age (final weight of $521 \mathrm{~kg}$ for PTHL group vs. $522 \mathrm{~kg}$ for CON). In particular, the PTHL group received $35 \mathrm{~g} /$ day per head for 90 days and $70 \mathrm{~g} /$ day per head for the last 30 days, administered directly in the mouth using a large syringe. The chemical composition of experimental diets, the PTHL composition, and its antioxidant activity were previously reported by Maggiolino et al. (5).

\section{Blood Samples and PBMC Isolation}

At 120 days of the experiment, blood samples from animals were collected from the jugular vein into sterile vacuum tubes containing EDTA (Becton Dickinson). All experiments were performed using PBMCs obtained from 10 beef steers ( $n=4$ for the PTHL group, and $n=6$ for the CON group).

PBMCs were isolated by Histopaque ${ }^{\circledR}-1077$ density gradient (Sigma-Aldrich, Milan, Italy) according to Wattegedera et al. (17). Briefly, whole blood diluted 1:1 with cold PBS was centrifuged, and the white cell rings recovered after centrifugation were diluted in Hanks' balanced salt solution (HBSS) and slowly layered on the Histopaque ${ }^{\circledR}-1077$ solution $(10 \mathrm{ml})$. The tubes were centrifuged at $400 \mathrm{~g}$ for $30 \mathrm{~min}$ at $20^{\circ} \mathrm{C}$, 
and the buffy coat, containing the PBMCs, layered on the upper layer of Ficoll-Paque, was recovered. The PBMC suspension was washed three times with HBSS wash buffer containing $2 \%$ fetal bovine serum (FBS), $50 \mu \mathrm{g} / \mathrm{ml}$ gentamicin (SigmaAldrich, Milan, Italy), and heparin (Sigma-Aldrich, Milan, Italy). Finally, PBMCs were resuspended in Iscove's Modified Dulbecco's medium (IMDM), without calcium and magnesium (Sigma-Aldrich, Milan, Italy) containing 10\% FBS and $50 \mu \mathrm{g} / \mathrm{ml}$ gentamicin. PBMCs were counted in a Burker cell counting chamber, and the viability of cells was obtained by Trypan blue (>98\%, Sigma-Aldrich, Milan, Italy) dye exclusion.

\section{Determination of Proliferation Assay and Viability \\ BrdU Assay}

Cell suspension, containing $2 \times 10^{6}$ cells $/ \mathrm{ml}$, was seeded into 96-well U-bottom plate into quadruplicate to carry out the proliferative response. PBMCs from the CON and PTHL group were stimulated with concanavalin A (ConA, at a final concentration of $5 \mu \mathrm{g} / \mathrm{ml}$ ) and lipopolysaccharide (LPS, at a final concentration of $1 \mu \mathrm{g} / \mathrm{ml}$ ). The concentration of both ConA and LPS used in in vitro trial was according to Ciliberti et al. (18). PBMCs stimulated with ConA and LPS were challenged with $4 \mathrm{mM}$ (19) of $\mathrm{H}_{2} \mathrm{O}_{2}$ solution in the culture medium (OS $\mathrm{H}_{2} \mathrm{O}_{2}$-mediated) as OS inducer. PBMCs cultured in medium without stimulation represented the negative control. PBMCs stimulated with ConA and LPS represented the positive control. The plates were incubated at $37^{\circ} \mathrm{C}$ and $5 \% \mathrm{CO}_{2}$ in a humidified incubator for $24 \mathrm{~h}$. After incubation time, plates were centrifuged, and cell-free supernatants from each well were collected and stored at $-20^{\circ} \mathrm{C}$ until ELISA to measure cytokine production and oxidant status.

After $24 \mathrm{~h}$, a proliferation test was performed based on incorporation of bromodeoxyuridine (BrdU) in dividing cells using a commercial kit (Roche); briefly, BrdU is added to the cells and the cells were reincubated for $18 \mathrm{~h}$; during this labeling period, the pyrimidine analog BrdU is incorporated in place of thymidine into the DNA of proliferating cells. Then, the culture medium was removed and the cells were fixed and subjected to DNA denaturation in one step. The BrdU incorporated during DNA synthesis was measured by ELISA using a monoclonal antibody from mouse-mouse hybrid cells (clone BMG 6H8, Fab fragments) conjugated with peroxidase and reading optical density with a plate reader spectrophotometer (Power Wave XS, Biotek, UK) at $450 \mathrm{~nm}$ was performed.

\section{Evaluation of PBMC Viability by Fluorescent Imaging}

PBMCs $\left(1 \times 10^{6}\right.$ cells $\left./ \mathrm{ml}\right)$ were seeded into 96 -well flat-bottom plate into duplicate to determine the viability or cytotoxic effect of treatment on PBMCs $(n=2 \mathrm{CON}$ group, $n=2$ PTHL group). PBMCs were untreated (UNC), treated with LPS and ConA (SC, $1 \mu \mathrm{g} / \mathrm{ml}$ and $5 \mu \mathrm{g} / \mathrm{ml}$, respectively), and with $4 \mathrm{mM}$ of $\mathrm{H}_{2} \mathrm{O}_{2}$, and incubated for $24 \mathrm{~h}$ at $37^{\circ} \mathrm{C} / 5 \% \mathrm{CO}_{2}$. Then, PBMCs were stained with Image-iT ${ }^{\circledR}$ DEAD Green ${ }^{\mathrm{TM}}$ viability stain (Molecular Probes, Milan, Italy) for $30 \mathrm{~min}$, fixed, permeabilized according to the manufacturer's instruction, and imaged on Life Technologies EVOS ${ }^{\mathrm{TM}}$ XL Imaging System (Milan, Italy). The
Image-iT ${ }^{\circledR}$ DEAD Green ${ }^{\mathrm{TM}}$ is an impermeant dye when there is integrity of plasma membrane, whereas it is permeant when the integrity of membrane is compromised. The nucleus was detected with Hoechst 33342 in the DAPI/Hoechst channel, and the cell membrane permeability was detected in the FITC/GFP channel.

\section{Assessment of Viability, Apoptosis, and Necrosis of PBMCs With Supravital Exposure to Propidium lodide by Flow Cytometer}

$\operatorname{PBMC}\left(1 \times 10^{6}\right.$ cells $\left./ \mathrm{ml}\right)$ suspensions were added into polystyrene round bottom tubes for cytofluorimetric analysis and treated with LPS and ConA ( 1 and $5 \mu \mathrm{g} / \mathrm{ml}$, respectively), and with $4 \mathrm{mM}$ of $\mathrm{H}_{2} \mathrm{O}_{2}$ for $1 \mathrm{~h}$. Then, supravital PI staining (SigmaAldrich, Milan, Italy, $50 \mu \mathrm{g} / \mathrm{ml}$ ) on non-permeabilized cells for $30 \mathrm{~min}$ in the dark was performed according to Zamai et al. (20). The cells were washed with PBS and analyzed by flow cytometry. The positive control to PI was represented by cells treated with $0.2 \%$ Triton-X (diluted in PBS with $2 \%$ BSA). Negative control was represented by cells without PI staining. Samples were analyzed by Attune NxT Flow Cytometer (Thermo Fisher). FSC and SSC analysis were performed at each experiment for monocyte/lymphocyte gate strategy, and cell doublet exclusion was carried out by SSC-A and SSC-H gating. The number of events was stopped at 10,000 counts, and the absolute counts of monocyte/lymphocyte were used for the evaluation of their viability, apoptosis, and necrosis considering that apoptotic cells have decreased FSC.

\section{Determination of ROS Production, Total Antioxidant Capacity, and AOB Index in Supernatants}

Relative levels of ROS in supernatants were measured according to the manufacturer's instructions of OxiSelect ${ }^{\mathrm{TM}}$ in vitro ROS/RNS Assay Kit Green Fluorescence (Cell Biolabs Inc, ell Biolabs Inc., San Diego, CA) based on reaction of ROS and RNS species with $2^{\prime}, 7^{\prime}$-dichlorodihydrofluorescin (DCFH), which is rapidly oxidized to the highly fluorescent $2^{\prime}, 7^{\prime}$ dichlorodihydrofluorescein (DCF). Green fluorescence was read with a fluorescence plate reader at $480 \mathrm{~nm}$ excitation $/ 530 \mathrm{~nm}$ emission (CLARIOstar microplate reader, BMG Labtech, Ortenberg, Germany). The fluorescence of blank samples was subtracted from sample measurements to eliminate background fluorescence. Results were read against DCF (1:10 scalar dilution with a concentration range of $0-10,000 \mathrm{nM}$ ) standard curve; the fluorescence intensity was directly proportional to the total ROS/RNS levels within the sample and was expressed as micromolar of DCF. Total antioxidant capacity (TAC) level in supernatants was evaluated using OxiSelect ${ }^{\mathrm{TM}}$ TAC Assay Kit (Cell Biolabs, Inc), according to the manufacturer's instructions. Briefly, this assay is based on the reduction of copper (II) to copper (I) by antioxidants such as uric acid. The maximum absorbance at $490 \mathrm{~nm}$ was read against uric acid serial dilution standard curve $(0-1 \mathrm{mM})$. The absorbance values were proportional to the sample's total reductive capacity and results were expressed as " $\mu \mathrm{M}$ of Uric Acid Equivalents," proportional to the TAC of the samples. Both parameters of 
the redox balance were assessed together as the ratio of total antioxidant defenses and oxidants, namely, antioxidant oxidant balance (AOB), previously applied in Ciliberti et al. (21), where it was demonstrated a reliable index for the evaluation of the effects of diet on OS activated by heat stress exposition in sheep. Moreover, in human studies, it was applied in order to evaluate the antioxidant status of serum $(22,23)$ and after long-term intake of plant antioxidant-rich foods (24). An increase in the ratio indicates a lower risk for OS exposition due to a prompter antioxidant defense against pro-oxidant production.

\section{Determination of IL-10, IL-12, IL-8, IFN- $\gamma$, and TNF- $\alpha$ in Culture Supernatants by ELISA}

The ELISA for IL-10 and IL-12 in PBMC supernatants was determined according to Kwong et al. (25) and Hope et al. (26), with some modifications as previously reported in Ciliberti et al. (27). The sandwich ELISA was built using specific antibody against bovine IL-10 and IL-12 (AbD Serotec, Kidlington, UK). The plates were read at $450 \mathrm{~nm}$ by a spectrophotometer (Power Wave XS, Biotek). Data were expressed as nanograms per milliliter for both IL-10 and IL-12. The intra-assay coefficients of variation (CV) were $9.46 \%$ for IL-10 and 10\% for IL- 12 .

The IL- 8 , IFN- $\gamma$, and TNF- $\alpha$ in supernatants were assayed using 96-well plates (Sterilin, Cambridge, UK), coated overnight at $4{ }^{\circ} \mathrm{C}$ with $100 \mu \mathrm{l}$ of mouse anti-ovine interleukin- 8 antibody (with checked bovine cross reaction, Kingfisher Biotech, St. Paul, $\mathrm{MN}$ ), anti-bovine IFN- $\gamma$ (AbD Serotec, Kidlington, UK), and anti-bovine TNF- $\alpha$ (AbD Serotec, Kidlington, UK) antibodies dissolved in PBS for IL-8 $(2 \mu \mathrm{g} / \mathrm{ml}$ final concentration) and carbonate buffer $\mathrm{pH} 9.6$ for IFN- $\gamma(2 \mu \mathrm{g} / \mathrm{ml}$, final concentration) and TNF- $\alpha(5 \mu \mathrm{g} / \mathrm{ml}$, final concentration), respectively. After washing four times with PBST (PBS/Tween 20, 0.05\%), the blocking solution including bovine serum albumin (PBST/BSA $3 \%$ ) was added into wells for $1 \mathrm{~h}$. Interleukin-8, IFN- $\gamma$, and TNF$\alpha$ secretion in supernatants were calculated against a standard curve using recombinant protein specific for bovine, and the standards and supernatants were added into wells and incubated for $1 \mathrm{~h}$; subsequently, the plates were washed four times. Biotinylated secondary anti-bovine IFN- $\gamma$ antibody $(2 \mu \mathrm{g} / \mathrm{ml}$, final concentration, AbD Serotec) and anti-bovine TNF- $\alpha$ antibody $(2.5 \mu \mathrm{g} / \mathrm{ml}$, final concentration in PBS, Kingfisher Biotech) dissolved in PBS were added for $45 \mathrm{~min}$. For the IL-8 antibody conjunction, the rabbit anti-sheep interleukin-8 $(2 \mu \mathrm{g} / \mathrm{ml}$, final concentration in PBS, AbD Serotec) was used and added to the wells for $1 \mathrm{~h}$. After washing four times, 100 $\mu l$ of streptavidin-horseradish peroxidase (HRP) (1/500, AbD Serotec) was added for IFN- $\gamma$ and TNF- $\alpha$ assay, whereas, for IL8 , a goat anti-rabbit IgG HRP-conjugated antibody $(1 / 20,000$ in PBS, Sigma-Aldrich, Italy) was added into wells. After washing, $100 \mu \mathrm{l}$ of 3,3',5,5'-tetramethylbenzidine (TMB, Sigma-Aldrich, Milan, Italy) substrate solution was added to each well and the colorimetric reaction was stopped adding $\mathrm{H}_{2} \mathrm{SO}_{4}(1 \mathrm{M})$. All plates were read at $450 \mathrm{~nm}$ by a spectrophotometer (Power Wave XS, Biotek). Data were expressed as nanograms per milliliter for both IL- 8 and TNF- $\alpha$, and the level of IFN- $\gamma$ was measured as

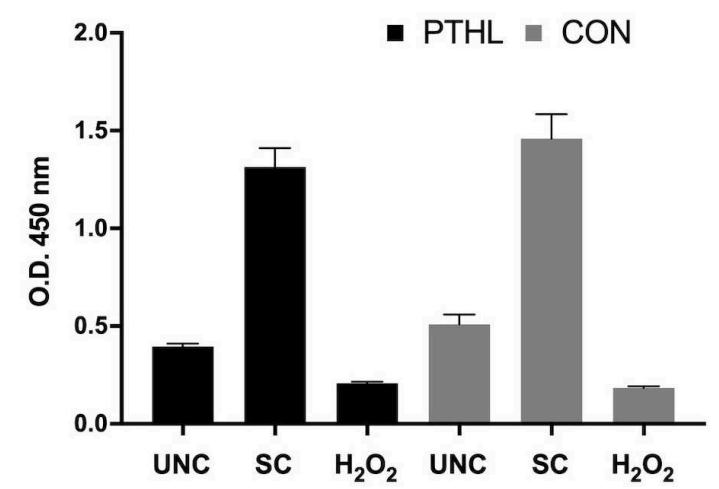

FIGURE 1 | BrdU incorporation in proliferating PBMCs isolated by blood of beef steers supplemented with Pinus taeda hydrolyzed lignin (PTHL) and with a control diet (CON). Cells were unstimulated (USC), stimulated with LPS and ConA (SC, 1 and $5 \mu \mathrm{g} / \mathrm{ml}$, respectively) and with $4 \mathrm{mM}$ of $\mathrm{H}_{2} \mathrm{O}_{2}$, and incubated for $24 \mathrm{~h}$ at $37^{\circ} \mathrm{C} / 5 \% \mathrm{CO}_{2}$.

picograms per milliliter. The intra-assay CV was around $10 \%$ for IL-8, IFN- $\gamma$, and TNF- $\alpha$.

\section{Statistical Analysis}

All data are presented as mean \pm SEM. Data were checked for normality test and analyzed with mixed ANOVA model of SAS (28). The model included the fixed effects of in vitro treatment (UNC, SC, and $\mathrm{H}_{2} \mathrm{O}_{2}$ ), the feeding strategy (CON and PTHL), and their interaction. Animals are included in the model as random effect. The significance of the differences was assessed using Tukey post hoc test for multiple comparisons and the $P$ value of $<0.05$ was considered statistically significant. Pearson correlation analysis was performed to correlate panel of cytokine, OS measurenments and proliferation of PBMCs.

\section{RESULTS}

\section{PBMC Proliferation and Viability by Fluorescent Imaging}

The BrdU incorporation in dividing cells was influenced by the in vitro treatments $(P<0.0001)$ and by the interaction between in vitro treatment and feeding strategy $(P=0.0002)$. No significant differences were registered in PBMCs from the PTHL group and the CON group (Figure 1). The intense proliferative response of PBMCs and their viability emerged using Green Image$\mathrm{iT}^{\circledR}$ DEAD Green ${ }^{\mathrm{TM}}$ viability stain. In Figure 2, the membrane permeability (green) and its merge with nuclear morphology (blue) of PBMCs from the CON group (a) and the PTHL group (b) are represented. In UNC and in the $\mathrm{H}_{2} \mathrm{O}_{2}$ treatment, the viability clearly decreased with respect to SC in both $\mathrm{CON}$ and PTHL groups. However, in the PTHL group, the cell viability, as depicted from merging images from nuclear and membrane permeability (blue and green stain), was higher than in the CON group; this result was particularly apparent when comparing the viability of total cell number after $\mathrm{OS}_{2} \mathrm{O}_{2}$-mediated treatment. 


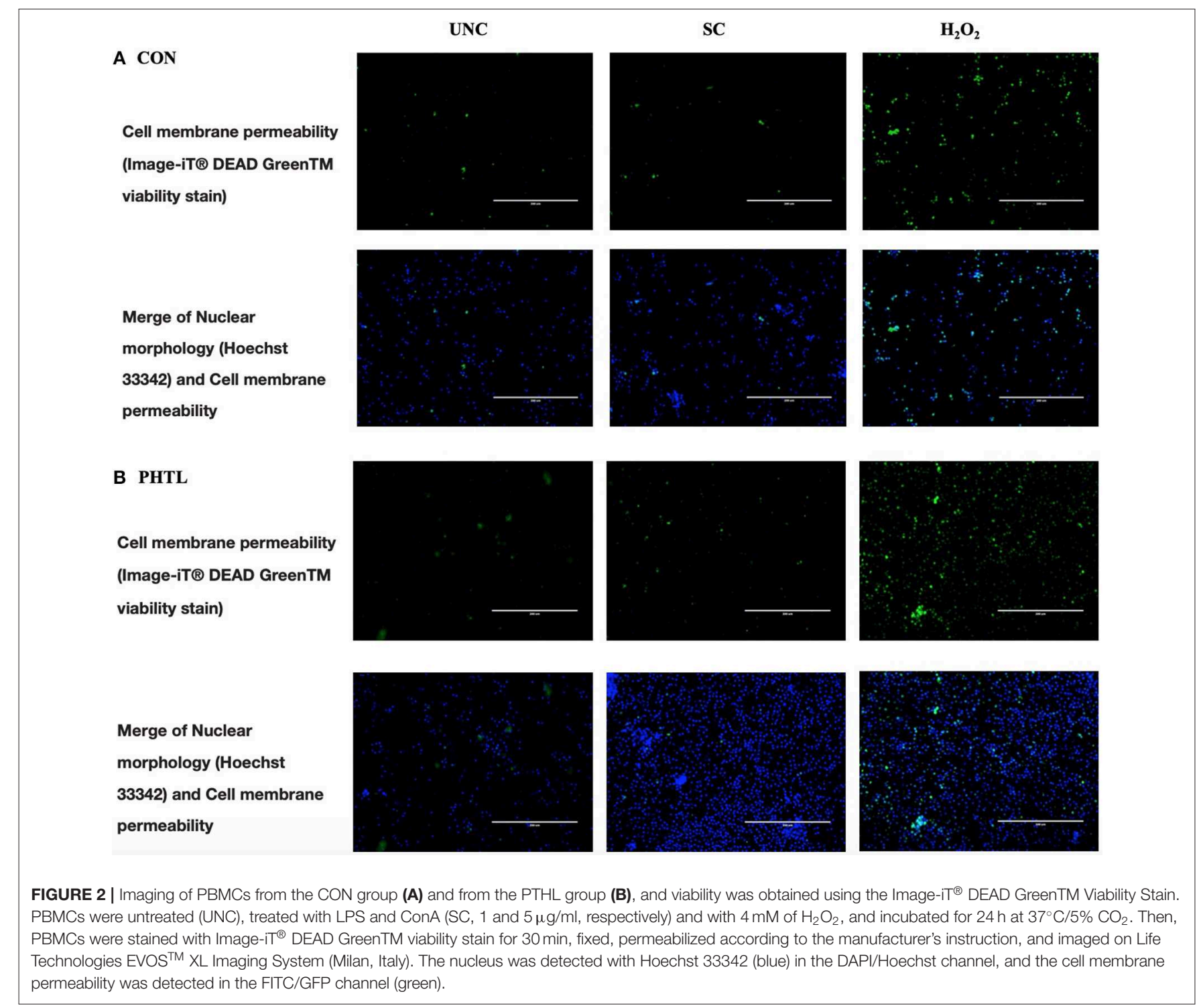

\section{Viability, Apoptosis, and Necrosis of PBMCs With Supravital Exposure to Propidium lodide by Flow Cytometer}

When measuring cell viability by flow cytometer, both monocyte and lymphocyte population characteristics of PBMCs can be discriminated by FSC and SSC analysis. Exposure to propidium iodide at supravital dose is a reliable method to concomitantly identify the detection of living (PI negative), apoptotic (PI dim), and necrotic (PI bright) cells. After gating of monocytes and lymphocytes, the percentages of viable (Figure 3A), apoptotic (Figure 3B), and necrotic (Figure 3C) cells of each population were measured in both the CON and PTHL group. After $1 \mathrm{~h}$ of $\mathrm{H}_{2} \mathrm{O}_{2}$ treatment, the lymphocytes in both the PTHL and CON group did not register a decrease in viability, whereas monocyte viability decreased in the CON group in comparison with the PTHL group $(P=0.03)$. As a consequence, in the CON group, the majority of monocyte population seemed to undergo necrosis, while in the PTHL group, the monocyte viability was around $35.7 \%$ without $\mathrm{H}_{2} \mathrm{O}_{2}$ treatment and $31.9 \%$ after $1 \mathrm{~h}$ of $\mathrm{H}_{2} \mathrm{O}_{2}$ treatment. Thus, results demonstrated that the lignin administration in the PTHL group was able to protect monocytes from necrosis.

\section{ROS/RNS Production, TAC, and AOB Index in Supernatants}

Total ROS/RNS production in supernatants from PBMCs was influenced by feeding strategy $(P=0.03)$ and by in vitro stimulation $(P<0.0001)$. On average, ROS/RNS production was higher in the CON group than in the PTHL group. The PTHL group resulted in a lower ROS/RNS production than the $\mathrm{CON}$ group after $\mathrm{H}_{2} \mathrm{O}_{2}$ treatment, and as expected, the unstimulated cells of both groups showed lower ROS/RNS production than stimulated PBMCs (Figure 4A). The TAC significantly decreased when adding $\mathrm{H}_{2} \mathrm{O}_{2}$ to both PTHL and 

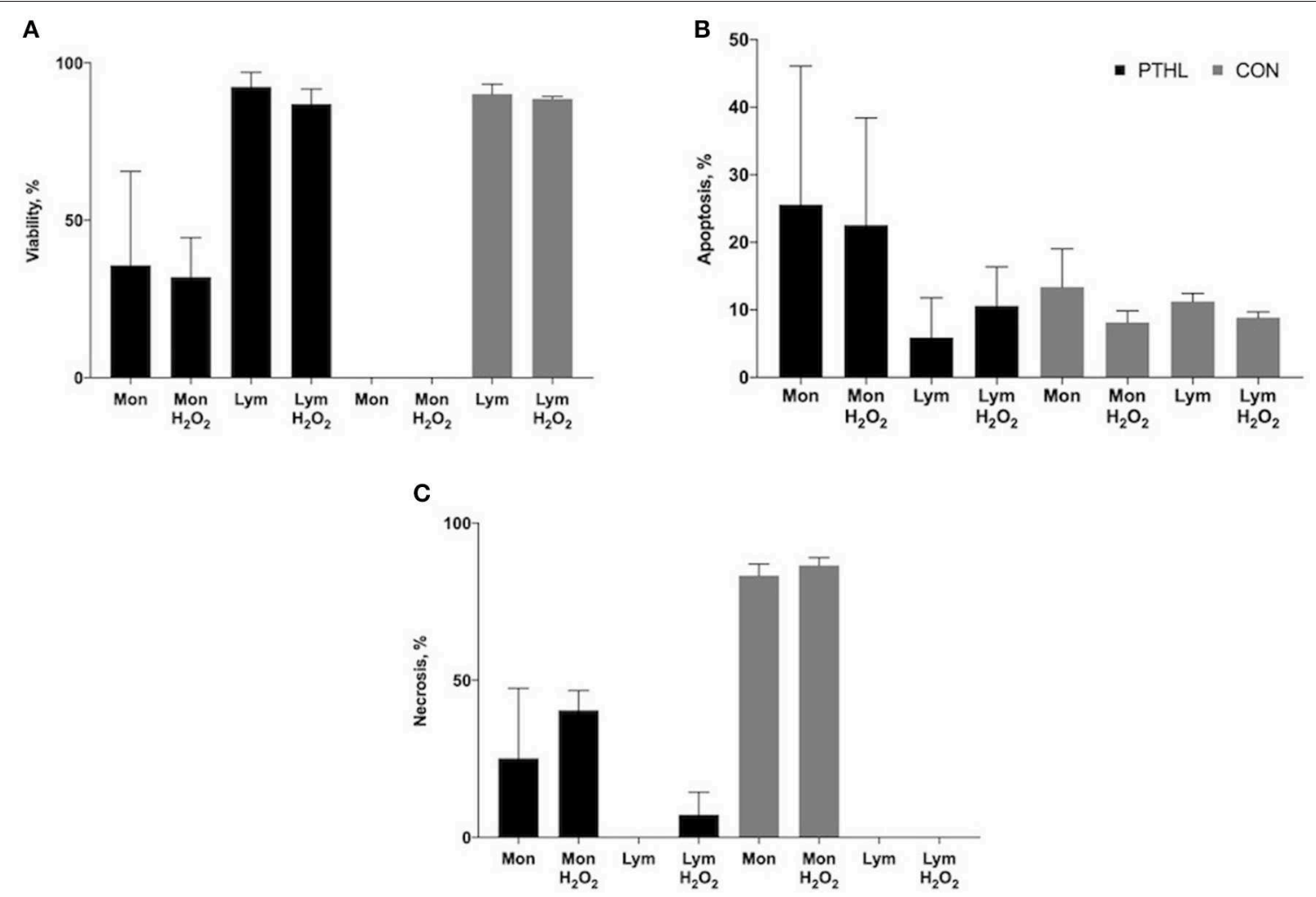

FIGURE 3 | Percentage of viability (A), apoptosis (B) and necrosis (C) of monocyte/lymphocyte stained with supravital exposure to propidium iodide (PI, $50 \mu \mathrm{g} / \mathrm{mL})$. Cells $(1 \times 106)$ were pretreated with LPS and ConA $\left(1 \mu \mathrm{g} / \mathrm{mL}\right.$ and $5 \mu \mathrm{g} / \mathrm{mL}$, respectively) and with $\mathrm{H}_{2} \mathrm{O}_{2}(4 \mathrm{mM})$ for $1 \mathrm{~h}$, then stained with PI for $30 \mathrm{~min}$ at the dark and washed before flow cytometric analysis. The supravital PI exposure on unfixed cells allowed to the simultaneous detection of living (PI negative) apoptotic (PI dim) and necrotic (PI bright) cells.

CON PBMCs $(P<0.0001)$. No significant differences in the TAC levels in supernatant between experimental groups were found (Figure 4B). When the AOB was calculated in order to verify the antioxidant status of PBMC supernatants, no differences between experimental groups, also during $\mathrm{H}_{2} \mathrm{O}_{2}$ exposition, were found (Figure 4C).

\section{Production of IL-10, IL-12, IL-8, IFN- $\gamma$, and TNF- $\alpha$ in PBMC Supernatants by ELISA}

As regards the cytokine secretion, the production of IL-10 by PBMCs was not affected by diet supplementation, registering a significant effect in relation to in vitro treatment $(P=0.0014)$. In particular, in the CON group, the $\mathrm{H}_{2} \mathrm{O}_{2}$ treatment resulted in a decrease of IL-10 production in comparison with IL10 production from UNC PBMCs $(P=0.0076$, Figure 5A), whereas the IL-12 production did not result in any significant differences among experimental diet and in vitro stimulation (Figure 5B). Furthermore, the in vitro treatment affected the IL8 production $(P<0.0001)$, showing a significant interaction between diet supplementation and in vitro treatment $(P=$ 0.0002). On average, the IL-8 production of SC was the highest followed by UNC and $\mathrm{H}_{2} \mathrm{O}_{2}$-treated PBMCs, respectively. Moreover, the SC PBMCs from the PTHL group produced higher IL-8 than SC PBMCs from the CON group $(P=0.049$, Figure 5C).

The production of IFN- $\gamma$ was significantly driven by in vitro stimulation $(P<0.0001)$; both UNC- and $\mathrm{H}_{2} \mathrm{O}_{2}$-treated PMBCs from the PTHL and CON group had lower IFN- $\gamma$ production than SC PBMCs (Figure 5D). Finally, the TNF- $\alpha$ production in SC PBMCs from the PTHL group was significantly decreased with respect to SC PBMC from the CON group $(P=0.019$, Figure 5E).

Correlation coefficients $(r)$ of the panel of cytokines, OS measurements, and proliferation of PBMCs from the PTHL and CON group were represented as heat map in Figure 6. In the PTHL group, IL-8 positively correlated with TNF- $\alpha$, IFN $-\gamma$, and proliferation $(P<0.05)$; additionally, both TNF- $\alpha$ and IFN- $\gamma$ correlated with proliferation $(P<0.05)$. In the CON group, IL10 was found to be positively correlated with ROS and AOB; IL-8 correlated with TAC, ROS, AOB, and proliferation $(P<0.05)$.

\section{DISCUSSION}

The present study has provided evidence that in vivo supplementation with $P$. taeda hydrolyzed lignin (PTHL) of beef steers is able to influence the immune response, 

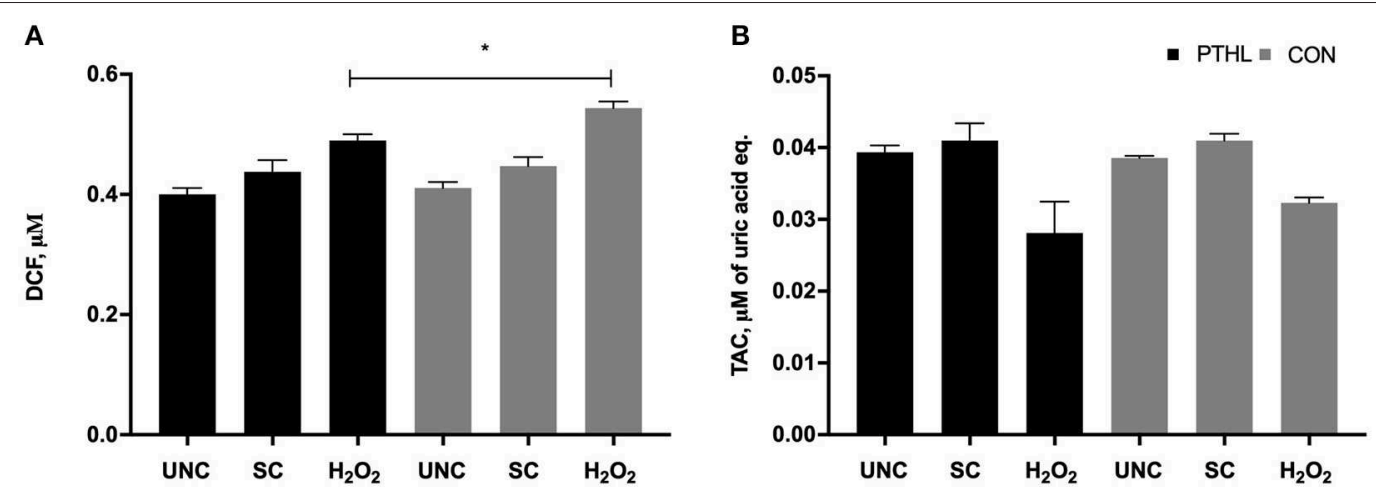

C

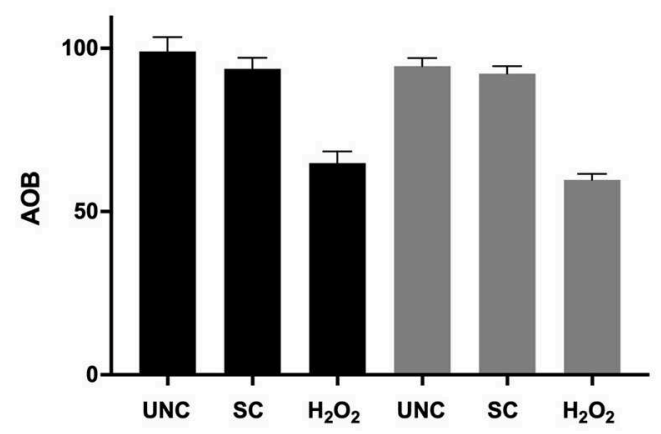

FIGURE 4 | ROS/RNS production measured as micromolar of DCF (A), total antioxidant capacity measured as micromolar of uric acid equivalents, (B) and Antioxidant/Oxidant Balance (AOB = TAC/ROS-RNS) (C) in supernatant of PBMCs unstimulated (UNC) and stimulated with LPS and ConA (SC, 1 and $5 \mu \mathrm{g} / \mathrm{ml}$, respectively) and with $4 \mathrm{mM}$ of $\mathrm{H}_{2} \mathrm{O}_{2}$ for $24 \mathrm{~h}$ at $37^{\circ} \mathrm{C} / 5 \% \mathrm{CO}_{2} \cdot{ }^{\star} P<0.05$ were considered significant among feeding strategy.

modifying cellular apoptosis/necrosis and viability, the oxidative status, and the cytokine profile of PBMCs treated with $\mathrm{H}_{2} \mathrm{O}_{2}$.

Hydrogen peroxide, being a major ROS, can be considered an activator of OS in different cellular models responsible for cell death and apoptotic variations (29-31). In the present paper, the inclusion of $\mathrm{H}_{2} \mathrm{O}_{2}$ treatment at $4 \mathrm{mM}$ was used in order to cause OS, as previously reported in Asiaei et al. (19). Furthermore, in vitro investigations utilize mitogens, such as ConA and phytohemagglutinin, which can activate mammalian $\mathrm{T}$-cell proliferation via mitosis stimulation (32, 33); thus, mitogens are used in defining the non-specific cellular immune response. Besides, blastogenic responses of bovine peripheral blood leukocytes stimulated with E. coli LPS, as an activator of bovine B-cell mitosis, are enhanced by immunization with heterologous bacteria (34). In a previous study, LPS stimulation was used for simulating an in vitro persistent inflammatory response causing a decreasing of cell viability and enhancement of inflammatory cytokine synthesis (35). The blastogenic response of bovine PBMCs to LPS in vitro was found to be correlated with disease resistance of periparturient dairy cows (36). In the present study, PBMCs isolated from blood of beef steers were stimulated with ConA and LPS in order to stimulate both
$\mathrm{T}$ and $\mathrm{B}$ cells during OS exposition and evaluate a more comprehensive effect of PTHL on immune competence mediated by cytokine production.

The PTHL supplementation did not cause an enhancement of proliferative response to BrdU incorporation; however, the increased levels of proliferation in response to mitogens in both experimental groups demonstrated that in vitro proliferative induction could be representative of cellular immunocompetence (37). The blastogenic response to LPS has been previously considered as a useful prognostic parameter of the host's coping ability with respect to environmental, infectious, and noninfectious stressors (38). The OS in vitro treatment was not counterbalanced by PTHL in vivo supplementation as regards the proliferative response; however, hydrolyzed lignin contributed to determine a major viability of PBMCs as demonstrated by fluorescent imaging and flow cytometry assays. The hypothesis of a possible cytoprotective role of PTHL on PBMCs was suggested by the decrease of cell membrane permeability in PBMCs from the PTHL group detected by fluorescent microscopy. Indeed, when the viability was evaluated by flow cytometry, using the supravital dose of PI, the cytoprotective role of PTHL emerged, particularly on monocytes. The principle of cytometric analysis for detecting viability, apoptosis, and necrosis of cells is based 


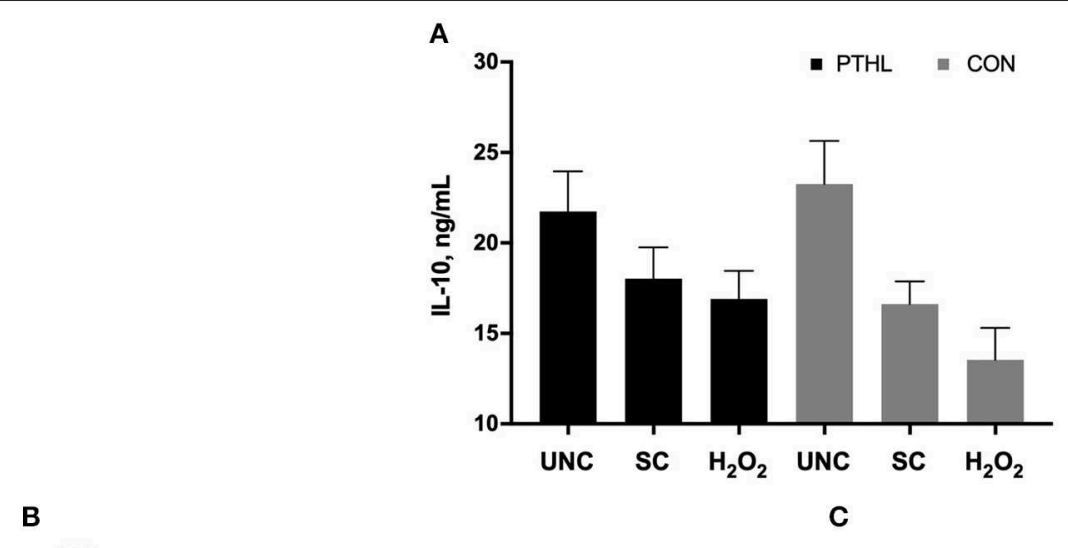

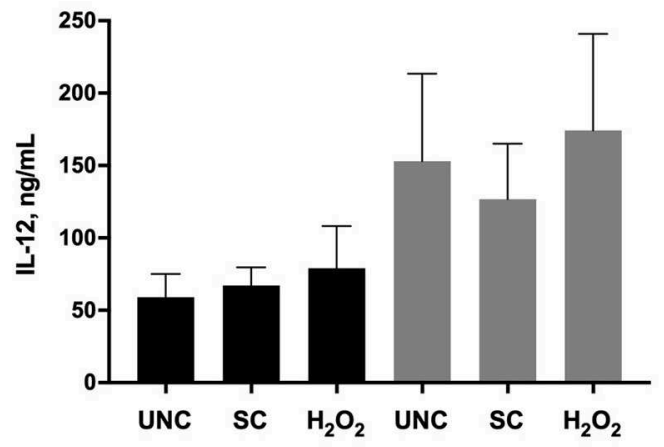

D

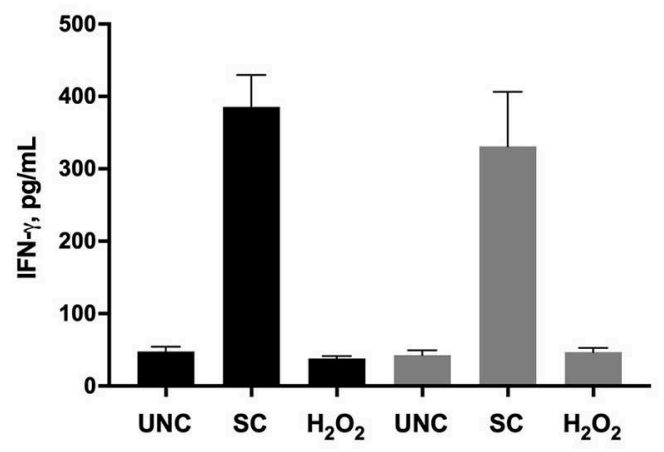

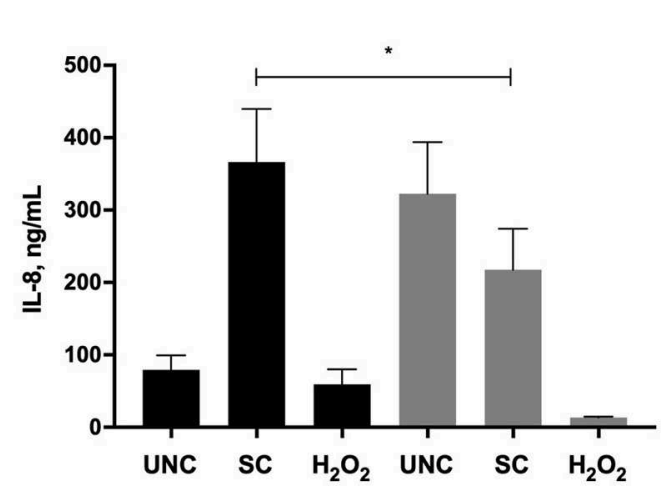

E

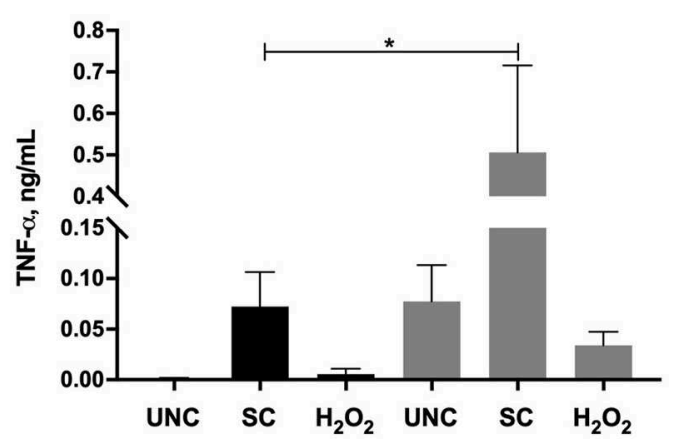

FIGURE 5 | Interleukin (IL)-10 (A), IL-12 (B), IL-8 (C), interferon-(IFN)- $\gamma$, (D), tumor necrosis factor (TNF)- $\alpha$, and (E) secretion by PBMCs unstimulated (UNC) and stimulated with LPS and ConA (SC, 1 and $5 \mu \mathrm{g} / \mathrm{ml}$, respectively) and with $4 \mathrm{mM}$ of $\mathrm{H}_{2} \mathrm{O}_{2}$ for $24 \mathrm{~h}$ at $37^{\circ} \mathrm{C} / 5 \% \mathrm{CO}_{2}$. ${ }^{\star} P<0.05$ were considered significant among feeding strategy.

on light scattering changes during apoptosis, with cells being smaller, and the intensity of side scatter diminished. In contrast, during necrosis, both light scatter parameters decreased, caused by loss of membrane permeability and leakage of cytoplasmic constituents (39). The protective role of hydrolyzed lignin against apoptosis and necrosis was emphasized by the presence of a percentage of viable monocytes also during OS $\mathrm{H}_{2} \mathrm{O}_{2}$ mediated in vitro treatment in the PTHL group. In contrast, the CON group did not register any viable monocytes, which are mainly gone due to the irreversible necrosis process. The plethora of different assays is strongly requested to crossanalyze the actions of PTHL on changing cell morphology given better information about the role of hydrolyzed lignin on PBMCs (40).

The composition of PTHL extract contained flavonoids and polyphenols that account for its total antioxidant activity. The PTHL supplementation contributed to reduce ROS/RNS production by PBMCs exposed to OS $\mathrm{H}_{2} \mathrm{O}_{2}$-mediated treatment; however, a slight reduction of TAC in both groups exposed to OS $\mathrm{H}_{2} \mathrm{O}_{2}$-mediated treatment as a response of counterbalancing of oxidant products was registered. The absence of an increase in TAC in the PTHL group could be explained by the dual role of flavonoids as antioxidant and pro-oxidant in relation to their concentration. Schmalhausen et al. (41) reported 


\begin{tabular}{|c|c|c|c|c|c|c|c|c|c|c|}
\hline & Group & IL-10 & II-12 & IL-8 & IFN- $\gamma$ & TNF- $\alpha$ & TAC & ROS & АОВ & Proliferation \\
\hline \multirow[t]{2}{*}{ IL-10 } & PTHL & 1.00 & 0.03 & 0.32 & 0.13 & -0.30 & 0.53 & -0.02 & 0.48 & 0.47 \\
\hline & $\mathrm{CON}$ & 1.00 & 0.12 & 0.44 & -0.20 & 0.06 & 0.10 & $-0.68^{*}$ & $0.58^{*}$ & 0.00 \\
\hline \multirow[t]{2}{*}{ II-12 } & PTHL & & 1.00 & 0.16 & -0.08 & 0.20 & -0.13 & 0.20 & -0.22 & 0.07 \\
\hline & CON & & 1.00 & -0.24 & -0.15 & -0.09 & -0.29 & 0.06 & -0.20 & -0.22 \\
\hline \multirow[t]{2}{*}{ IL-8 } & PTHL & & & 1.00 & $0.89^{*}$ & $0.70^{*}$ & 0.25 & -0.28 & 0.33 & $0.84^{*}$ \\
\hline & $\mathrm{CON}$ & & & 1.00 & 0.21 & 0.27 & $0.59^{*}$ & -0.38 & 0.52 & $0.48^{*}$ \\
\hline \multirow[t]{2}{*}{ IFN- $\gamma$} & PTHL & & & & 1.00 & 0.39 & 0.27 & -0.14 & 0.24 & $0.89^{*}$ \\
\hline & $\mathrm{CON}$ & & & & 1.00 & $0.37^{*}$ & $0.57^{*}$ & -0.07 & 0.28 & $0.86^{*}$ \\
\hline \multirow[t]{2}{*}{ TNF- $\alpha$} & PTHL & & & & & 1.00 & 0.07 & -0.41 & 0.31 & $0.58^{*}$ \\
\hline & $\mathrm{CON}$ & & & & & 1.00 & $0.43^{*}$ & -0.02 & 0.18 & 0.28 \\
\hline \multirow[t]{2}{*}{ TAC } & PTHL & & & & & & $1.00^{*}$ & -0.07 & 0.76 & 0.37 \\
\hline & $\mathrm{CON}$ & & & & & & 1.00 & $-0.48^{*}$ & 0.77 & $0.72^{*}$ \\
\hline \multirow[t]{2}{*}{ ROS } & PTHL & & & & & & & 1.00 & $-0.69^{*}$ & -0.17 \\
\hline & $\mathrm{CON}$ & & & & & & & 1.00 & $-0.92^{*}$ & -0.27 \\
\hline \multirow[t]{2}{*}{ AOB } & PTHL & & & & & & & & 1.00 & 0.33 \\
\hline & $\mathrm{CON}$ & & & & & & & & 1.00 & $0.53^{*}$ \\
\hline \multirow[t]{2}{*}{ Proliferation } & PTHL & & & & & & & & & 1.00 \\
\hline & CON & & & & & & & & & 1.00 \\
\hline
\end{tabular}

FIGURE 6 | Correlation analysis of panel of cytokine, oxidative stress measurements, and cell proliferation of the CON and PTHL group. ${ }^{*} P<0.05$.

that the flavonoid quercetin at concentrations higher than $200 \mu \mathrm{M}$ contributed to the formation of hydroxyl radical and production of $\mathrm{H}_{2} \mathrm{O}_{2}$, especially in the presence of metal ion; conversely, it protected from oxidation in the absence of a metal ion. Tea polyphenols tested in non-ruminant cells, both in vitro and in vivo, showed an antioxidant effect against ROSinduced disorders (42), directly by ROS scavenging and by stimulation of endogenous cellular defense systems (43). When $\mathrm{H}_{2} \mathrm{O}_{2}$ was tested at supraphysiologic dose in bovine mammary epithelial cells, the in vitro treatment with tea polyphenols stimulated the activity of antioxidant endogen enzymes, such as SOD and glutathione peroxidase (GSH-Px), and decreased ROS, malondialdehyde (MDA), protein carbonyl, 8-hydroxy-2'deoxyguanosine, 8-isoprostaglandin, and the activity of caspase3 , reducing the damage of proteins, DNA, and lipids (44). It has been demonstrated that cell susceptibility to $\mathrm{H}_{2} \mathrm{O}_{2}$ is dose dependent; in the memory $\mathrm{T}$ cells, susceptibility to $\mathrm{H}_{2} \mathrm{O}_{2}$ is lower than in effector $\mathrm{T}$ cells and Treg cells, exploiting their suppressive action also in the presence of micromolar levels of $\mathrm{H}_{2} \mathrm{O}_{2}$ (1). Owing to the above, we can hypothesize that dietary antioxidants as well as PTHL extract can contribute to immune cellular activity mediating the apoptosis and ROS production during $\mathrm{OS}_{2} \mathrm{O}_{2}$-mediated treatment.

Dietary antioxidants could modulate the inflammatory response with different mechanisms, via indirect control by antioxidant defense or interfering with the OS signaling; the direct action of dietary antioxidants on inflammation was the suppressive action on pro-inflammatory signaling transduction (45). Principally, it has been demonstrated that anti-oxidative activity and anti-inflammatory effects of phenolic compounds involve similar biomarkers. The key node that cross-links the signaling cascades between redox response and inflammation, caused by ROS overproduction at the mitochondrial level, was found to be the NLRP3 (NACHT, LRR, and PYD domain-containing protein 3) inflammasome assembly, which stimulates the synthesis of pro-inflammatory cytokines (46). The activated inflammasome, in a cascade mechanism, stimulates the release of cytokine IL-1 $\beta$ from cytoplasm into extracellular environment and activates Toll-like receptor (TRL)-1-mediated inflammatory signaling to produce IL- $1 \beta$, IL- 6 , IL- 8 , TNF$\alpha$, and IFN- $\gamma$. The activation of these cascades of signals serves to amplify the inflammatory response that is responsible for systemic inflammation (45). In the present experiment, dietary PTHL altered the release of TNF- $\alpha$ in supernatants of PBMCs exposed to stimulation, revealing a strong control of inflammatory response due to antioxidant compounds. The pluripotent cytokine TNF- $\alpha$ is considered to be the endogenous mediator of inflammation activating the cytokine cascade required for appropriate cellular responses in the target tissue (47). Circulating monocytes are the main cellular target of TNF$\alpha$, which is responsible for the phenotypic changes required for phagocytosis process and the induction of secretion of other inflammatory mediators, such as IL-8, which allows for the recruitment of neutrophils into the target tissue (47). Moreover, IL-8 is an important inflammation mediator that can be induced by ROS and suppressed by antioxidants in a celltype-specific fashion (48-50). Zhang et al. (51) demonstrated a novel paradigm in which the response of Nrf2 (NF-E2-related factor 2) to OS by inducing expression of cytoprotective and antioxidant genes that attenuate tissue injury, which is mediated by chemokine production and by an increase in IL- 8 after an initial inflammatory response, reduces inflammation, and preserves tissue integrity. This result may be relevant for limiting tissue injury diseases in which OS and inflammation play a prominent pathophysiologic role and should be considered for therapeutic strategy. The use of PTHL in the diet of beef steers allowed the increase of IL-8 secretion in stimulated PBMCs compared to CON. Based on this, and according to an increase of viability of monocytes in PTHL PBMCs, the dietary inclusion of PTHL clearly showed a cytoprotective role and a control of inflammation mediated by a decrease of TNF- $\alpha$ secretion, the concomitant increase of IL-8 secretion, and the reduction of ROS production. The presence of apoptotic cells during monocyte activation influences cytokine patterns by increasing IL-10 production and reducing pro-inflammatory cytokines; however, the changes in cytokine patterns from cells depend on 
incubation time (52). In the present experiment, incubation times of cells in which apoptosis and necrosis were measured differed from those of cells in which cytokines were measured. Based on this, cytokine results cannot be strictly interrelated with results from necrosis and apoptosis assay.

There exist a bimodal regulation between inflammatory response and OS; thus, a lower OS reduces the production of inflammatory cytokines and, in turn, a decrease in inflammatory cytokines is capable of decreasing the production of free radicals (53). Moreover, the interrelation between the control of immune responses and PTHL dietary administration was corroborated by the significant correlations found among TNF$\alpha$, IL-8, IFN- $\gamma$, and PBMC proliferation, whereas the significant correlations found in the CON group deeply demonstrated an inflammatory profile of PBMCs, mediated by a cross-talk between OS and cytokine production in which IL-10 correlated with ROS and AOB and IL-8 correlated with TAC, ROS, AOB, and $\mathrm{PBMC}$ proliferation.

\section{CONCLUSIONS}

In the present experiment, the effect of PTHL dietary supplementation on beef steers' immune cell function and cytokine profile during $\mathrm{OS} \mathrm{H}_{2} \mathrm{O}_{2}$-mediated treatment was addressed. The use of PTHL, rich in hydrolyzed lignin with an antioxidant effect, was able to protect cells from apoptosis/necrosis, due to OS exposition, increasing the number of viable monocytes, and decreasing the ROS/RNS production in supernatants. Furthermore, a modulation of inflammatory responses of PTHL supplementation emerged in PMBCs with a decrease of TNF- $\alpha$ and an increase of IL- 8 production, which are strictly connected with monocyte activation and

\section{REFERENCES}

1. Belikov AV, Schraven B, Simeoni LT. T cells and reactive oxygen species. $J$ Biomed Sci. (2015) 22:85. doi: 10.1186/s12929-015-0194-3

2. Colitti M, Stefanon B, Gabai G, Gelain ME, Bonsembiante F. Oxidative stress and nutraceuticals in the modulation of the immune function: current knowledge in animals of veterinary interest. Antioxidants. (2019) 8:28. doi: 10.3390/antiox8010028

3. Valacchi G, Virgili F, Cervellati C, Pecorelli A. OxInflammation: from subclinical condition to pathological biomarker. Front Physiol. (2018) 9:858. doi: $10.3389 /$ fphys.2018.00858

4. Maggiolino A, Rodriguez JML, Salzano A, Faccia M, Blando F, Serrano MP, et al. Effects of aging and dietary supplementation with polyphenols from Pinus Taeda Hydrolyzed Lignin on quality parameters, fatty acid profile and oxidative stability of beef. Anim Prod Sci. (accepted).

5. Maggiolino A, Lorenzo JM, Quiñones J, Latorre MA, Blando F, Centoducati G, et al. Effects of dietary supplementation with Pinus taeda hydrolyzed lignin on in vivo performances, in vitro nutrient apparent digestibility, and gas emission in beef steers. Anim Feed Sci Tech. (2019) 255:114217. doi: 10.1016/j.anifeedsci.2019.114217

6. Braicu C, Mehterov N, Vladimirov B, Sarafian V, Nabavi SM, Atanasov AG, et al. Nutrigenomics in cancer: revisiting the effects of natural compounds. Semin Cancers Biol. (2017) 46:84-106. doi: 10.1016/j.semcancer.2017. 06.011

7. Surh YJ. Cancer chemoprevention with dietary phytochemicals. Nat Rev Cancer. (2003) 3:768-80. doi: 10.1038/nrc1189 antioxidant response pathway. Data of the present study improved knowledge about the use of hydrolyzed lignin in the diet of ruminant emphasizing its antioxidant and immunological role. Results encourage further experimentations about the potential application of hydrolyzed lignin in dairy animals under OS due to physiological events.

\section{DATA AVAILABILITY STATEMENT}

The datasets generated for this study are available on request to the corresponding author.

\section{ETHICS STATEMENT}

The animal study was reviewed and approved by Ethics Committee for animal testing-CESA (Process number 2-X/17).

\section{AUTHOR CONTRIBUTIONS}

MC, MGC, and PD were involved in the original design of the study. PD was responsible for the on-farm trial. MGC, MA, and AS were responsible for analytical procedures and data analysis, and wrote the manuscript. All authors have read and approved the final version of the manuscript and contributed to the preparation of the manuscript.

\section{FUNDING}

The authors declare that this study received funding from Probios s.r.l., Brescia (Italy). The funder was not involved in the study design, collection, analysis, interpretation of data, the writing of this article or the decision to submit it for publication.

8. Barnes S. Nutritional genomics, polyphenols, diets, and their impact on dietetics. J Am Diet Assoc. (2008) 108:1888-95. doi: 10.1016/j.jada.2008. 08.014

9. Agrawal DK, Mishra PK. Curcumin and its analogues: potential anticancer agents. Med Res Rev. (2010) 30:818-60. doi: 10.1002/med. 20188

10. Sgorlon S, Stradaioli G, Zanin D, Stefanon B. Biochemical and molecular response to antioxidant supplementation in sheep. Small Rumin Res. (2006) 64:143-51. doi: 10.1016/j.smallrumres.2005.04.009

11. Song P, Kwon Y, Joo JY, Kim DG, Yoon JH. Secretomics to discover regulators in diseases. Int J Mol Sci. (2019) 20:3893. doi: 10.3390/ijms20 163893

12. Mauro D, Procopio L. Blockade of nitricoxide overproduction and oxidative stress by nigella sativa oil attenuates morphine-induced tolerance. Neurochem Res. (2011) 36:924-5. doi: 10.1007/s11064-010-0215-2

13. Gladine C, Rock E, Morand C, Bauchart D, Durand D. Bioavailability and antioxidant capacity of plant extracts rich in polyphenols, given as a single acute dose, in sheep made highly susceptible to lipoperoxidation. Br J Nutr. (2007) 98:691-701. doi: 10.1017/S00071145077 42666

14. Christaki E, Giannenas E, Bonos E, Florou-Paneri P. Innovative uses of aromatic plants as natural supplements in nutrition. In: Florou-Paner P, Christaki E, and Giannenas I, editors. Feed Additives, Aromatic Plants and Herbs in Animal Nutrition and Health. London, UK; San Diego, CA; Cambridge, MA; Oxford, UK: Academic Press (2020). p. 19-31. doi: 10.1016/B978-0-12-814700-9.00002-9 
15. Bajwa DS, Pourhashem G, Ullah AH, Bajwa SG. A concise review of current lignin production, applications, products and their environmental impact. Ind Crop Prod. (2019) 139:111526. doi: 10.1016/j.indcrop.2019. 111526

16. Agrawal A, Kaushik N, Biswas S. Derivatives and applications of lignin-An insight. The Sci Tech J. (2014) 1:30-6.

17. Wattegedera SK, Sills CJ, Howard JC, Hope CJ, McInnes G. Variability in cytokine production and cell proliferation by mitogen-activate ovine peripheral blood mono- nuclear cells: Modulation by interleukin (IL)-10 and IL-12. Vet Immunol Immunopathol. (2004) 102:67-76. doi: 10.1016/j.vetimm.2004.06.006

18. Ciliberti MG, Albenzio M, Francavilla M, Neglia G, Esposito L, Caroprese M. Extracts from Microalga Chlorella sorokiniana exert an anti-proliferative effect and modulate cytokines in sheep peripheral blood mononuclear cells. Animals. (2019) 9:45. doi: 10.3390/ani9020045

19. Asiaei E, Farshad M, Abdollahi M, Jamshidzadeh A, Akbarizadeh AR, Soltanzadeh MA. Antioxidant and protective effects of angipars ${ }^{\mathrm{TM}}$, a new herbal drug, on hydrogen peroxide-induced oxidative stress in HepG 2 and A549 cell lines. Jundishapur J Nat Pharm Prod. (2016) 11:13. doi: 10.17795/jjnpp-42944

20. Zamai L, Canonico B, Luchetti F, Ferri P, Melloni E, Guidotti L, et al. Supravital exposure to propidium iodide identifies apoptosis on adherent cells. Cytometry. (2001) 44:57-64. doi: 10.1002/10970320(20010501)44:1<57::AID-CYTO1082>3.0.CO;2-O

21. Ciliberti MG, Soccio M, Pastore D, Albenzio M, Sevi A, Caroprese M. Antioxidant/oxidant balance: application as a biomarker of the antioxidant status in plasma of ewes fed seaweed Ascophyllum nodosum and flaxseed under high ambient temperature. Small Rum Res. (2019) 170:102-8. doi: 10.1016/j.smallrumres.2018.11.005

22. Laus MN, Soccio M, Alfarano M, Pasqualone A, Lenucci MS, Di Miceli G, et al. Serum antioxidant capacity and peroxide level of seven healthy subjects after consumption of different foods. Data Brief. (2016) 9:818-22. doi: 10.1016/j.dib.2016.10.028

23. Laus MN, Soccio M, Alfarano M, Pasqualone A, Lenucci MS, Di Miceli G, et al. Different effectiveness of two pastas supplemented with either lipophilic or hydrophilic/phenolic antioxidants in affecting serum as evaluated by the novel Antioxidant/Oxidant Balance approach. Food Chem. (2017) 221:27888. doi: 10.1016/j.foodchem.2016.10.050

24. Soccio M, Laus MN, Alfarano M, Dalfino G, Panunzio MF, Pastore D. Antioxidant/oxidant balance as a novel approach to evaluate the effect on serum of long-term intake of plant antioxidant-rich foods. J Funct Foods. (2018) 40: 778-84. doi: 10.1016/j.jff.2017.12.012

25. Kwong LS, Hope JC, Thom ML, Sopp P, Duggan S, Bembridge GP, et al. Development of an ELISA for bovine IL-10. Vet Immunol Immunopathol. (2002) 85:213-23. doi: 10.1016/S0165-2427(02)00007-7

26. Hope JC, Kwong LS, Entrican G, Wattegedera S, Vordermeier HM, Sopp P, et al. Development of detection methods for ruminant interleukin (IL)12. J Immunol Methods. (2002) 266:117-26. doi: 10.1016/S0022-1759(02) 00113-8

27. Ciliberti MG, Albenzio M, Inghese C, Santillo A, Marino R, Sevi A, et al. Peripheral blood mononuclear cell proliferation and cytokine production in sheep as affected by cortisol level and duration of stress. J Dairy Sci. (2017) 100:750-6. doi: 10.3168/jds.2016-11688

28. SAS Institute. SAS Enterprise Guide: Statistics, Version 6.1 ed. Cary, NC: SAS Inst. Inc (2013).

29. Marabini L, Calo R, Braga PC. Protective effect of erdosteine metabolite I against hydrogen peroxide-induced oxidative DNA-damage in lung epithelial cells. Arzneimittel-Forsch. (2010) 61:700-6. doi: 10.1055/s-00311300590

30. Chen $\mathrm{X}$, Zhong $\mathrm{Z}$, Xu Z, Chen L, Wang Y. No protective effect of curcumin on hydrogen peroxide-induced cytotoxicity in HepG2 cells. Pharmacol Rep. (2011) 63:724-32. doi: 10.1016/S1734-1140(11) 70584-9

31. Sattayasai J, Chaonapan P, Arkaravichie T, Soi-Ampornkul R, Junnu $\mathrm{S}$, Charoensilp $\mathrm{P}$, et al. Protective effects of mangosteen extract on $\mathrm{H} 2 \mathrm{O} 2$ - induced cytotoxicity in SK-N-SH cells and scopolamineinduced memory impairment in mice. PLoS ONE. (2013) 8:85053. doi: 10.1371/journal.pone.0085053
32. Brown JC, Hunt RC. Lectins. Int Rev Cytol. (1978) 52:277-349. doi: 10.1016/S0074-7696(08)60758-5

33. Charoenpornsook K, Fitzpatrick JL, Smith JE. The effects four mycotoxins on the mitogen stimulated proliferation of bovine peripheral mononuclear cells in vitro. Mycopathologica. (1998) 143:105-11. doi: 10.1023/A:1006971 724678

34. Schurig GG, Duncan JR, Case J, Winter AJ. Blastogenic transformation by lipopolysaccharide of blood leukocytes from immunized but not normal cattle. Infect Immun. (1977) 17:463-5. doi: 10.1128/IAI.17.2.463465.1977

35. Basso FG, Soares DG, Pansani TN, Cardoso LM, Scheffel DL, de Souza Costa CA, et al. Proliferation, migration, and expression of oral-mucosalhealing-related genes by oral fibroblasts receiving low-level laser therapy after inflammatory cytokines challenge. Lasers Surg Med. (2016) 48:1006-14. doi: $10.1002 / 1 s m .22553$

36. Catalani E, Amadori M, Vitali A, Lacetera N. Short communication: lymphoproliferative response to lipopolysaccharide and incidence of infections in periparturient dairy cows. J Dairy Sci. (2013) 96:7077-81. doi: 10.3168/jds.2013-6854

37. Kristensson K, Kristensen L, Borrebaeck CAK, Carlsson R. Activation of human $\mathrm{CD}^{+}{ }^{+} 45 \mathrm{RA}^{+}$T-cells using B-cells as accessory cells. Immunol Lett. (1994) 39:223-9. doi: 10.1016/0165-2478(94)90162-7

38. Amadori, M. (2016). The Innate Immune Response to Noninfectious Stressors, Human and Animal Models. London, UK; San Diego, CA; Cambridge, MA; Oxford, UK: Elsevier Inc.; Academic Press.

39. Wlodkowic D, Telford W, Skommer J, Darzynkiewicz Z. Apoptosis and beyond: cytometry in studies of programmed cell death. Methods Cell Biol. (2011) 103:55-98. doi: 10.1016/B978-0-12-385493-3.00004-8

40. Smolewski P, Darzynkiewicz Z, Robak T. Caspase-mediated cell death in hematological malignancies: theoretical considerations, methods of assessment, and clinical implications. Leukemia Lymphoma. (2003) 44:1089-104. doi: 10.1080/104281903100 0077007.

41. Schmalhausen EV, Zhlobek EB, Shalova IN, Firuzi O, Saso L, Muronetz VI. Antioxidant and prooxidant effects of quercetin on glyceraldehyde3-phosphate dehydrogenase. Food Chem Toxicol. (2007) 45:1988-93. doi: 10.1016/j.fct.2007.04.015

42. Wiseman S, Balentine D, Frei B. Antioxidants in tea. Crit Rev Food Sci Nutr. (1997) 37:705-18. doi: 10.1080/10408399709527798

43. Shi X, Ye J, Leonard S, Ding M, Vallyathan V, Castranova V, et al. Antioxidant properties of (-)-epicatechin-3-gallate and its inhibition of Cr(VI)-induced DNA damage and Cr(IV)- or TPA-stimulated NF-kappaB activation. Mol Cell Biochem. (2000) 206:125-32. doi: 10.1023/A:1007012 403691

44. Ma YF, Zhao L, Coleman DN, Gao M, Loor JJ. Tea polyphenols protect bovine mammary epithelial cells from hydrogen peroxide-induced oxidative damage in vitro by activating NFE2L2/HMOX1 pathways. J Dairy Sci. (2019) 102:1-13. doi: 10.3168/jds.2018-15047

45. Zhang H, Tsao R. Dietary polyphenols, oxidative stress and antioxidant and anti-inflammatory effects. Curr Opin Food Sci. (2016) 8:33-42. doi: $10.1016 /$ j.cofs.2016.02.002

46. Vanaja SK, Rathinam VAK, Fitzgerald KA. Mechanisms of inflammasome activation: recent advances and novel insights. Trends Cell Biol. (2015) 25:30815. doi: 10.1016/j.tcb.2014.12.009

47. Vlahopoulos S, Boldogh I, Casola A, Brasier AR. Nuclear factor$\kappa \mathrm{B}$-dependent induction of interleukin-8 gene expression by tumor necrosis factor: evidence for an antioxidant sensitive activating pathway distinct from nuclear translocation. Blood. (1999) 94:1878-89. doi: 10.1182/blood.V94.6.1878

48. Wu HM, Chi KH, Lin WW. Proteasome inhibitors stimulate activator protein-1 pathway via reactive oxygen species production. FEBS Lett. (2002) 526:101-5. doi: 10.1016/S0014-5793(02)03151-4

49. Verhasselt V, Goldman M, Willems F. Oxidative stress up-regulates IL8 and TNF-alpha synthesis by human dendritic cells. Eur J Immunol. (1998) 28:3886-90. doi: 10.1002/(SICI)1521-4141(199811)28:11<3886::AIDIMMU3886>3.0.CO;2-M

50. Roebuck KA. Regulation of interleukin-8 gene expression. J Interf. Cytokine Res. (1999) 19:429-38. doi: 10.1080/1042819031000077007 
51. Zhang X, Chen X, Song H, Chen HZ, Rovin BH. Activation of the $\mathrm{Nrf2/antioxidant} \mathrm{response} \mathrm{pathway} \mathrm{increases} \mathrm{IL-8} \mathrm{expression.} \mathrm{Eur} \mathrm{J} \mathrm{Immunol.}$ (2005) 35:3258-67. doi: 10.1002/eji.200526116

52. Voll RE, Herrmann M, Roth EA, Stach C, Kalden JR, Girkontaite I. Immunosuppressive effects of apoptotic cells. Nature. (1997) 390:350-1. doi: $10.1038 / 37022$

53. Basiricò L, Morera P, Dipasquale D, Bernini R, Santi L, Romani A, et al. (-)-Epigallocatechin-3-gallate and hydroxytyrosol improved antioxidative and anti-inflammatory responses in bovine mammary epithelial cells. Animal. (2019) 13:2847-56. doi: 10.1017/S1751731119 001356
Conflict of Interest: The authors declare that the research was conducted in the absence of any commercial or financial relationships that could be construed as a potential conflict of interest.

Copyright (c) 2020 Ciliberti, Albenzio, De Palo, Santillo and Caroprese. This is an open-access article distributed under the terms of the Creative Commons Attribution License (CC BY). The use, distribution or reproduction in other forums is permitted, provided the original author(s) and the copyright owner(s) are credited and that the original publication in this journal is cited, in accordance with accepted academic practice. No use, distribution or reproduction is permitted which does not comply with these terms. 